\title{
Thermal Sensor Boiler Monitoring based on Wireless Sensing
}

\author{
https://doi.org/10.3991/ijoe.v14i08.9176 \\ Aixia Duan ${ }^{(\varpi)}$ \\ North China University of Water Resources and Electric Power, Henan, China \\ aixiaduan2783@126.com \\ Yongzhi Huang \\ Rundian Energy Science and Technology Co., Ltd., Henan 450000, China \\ Yanling Duan, Qiuhong Wang \\ North China University of Water Resources and Electric Power, Henan, China
}

\begin{abstract}
To solve the problems of traditional wiring monitoring methods, such as difficulty in wiring, high temperature, and premature aging of the lines, the development status and trend of ZigBee technology were analyzed. A ZigBee-based online gas leakage monitoring system for power plant boilers was designed to avoid gas leakage in these boilers. ZigBee short-range wireless communication technology was used instead of the wired method to complete online monitoring of power plant boilers. Results showed that the system timely monitored the gas leakage and revealed the operating status of the power plant boiler in real time. In addition, the next moment of gas leakage was predicted, which ensured the safe and stable operation of the power plant boiler. In summary, gray system theory provides powerful theoretical support for the leakage status assessment and gas leakage prediction of the boiler. The proposed system ensures the safe, stable, and efficient operation of the power plant boiler.
\end{abstract}

Keywords-power plant boiler, wireless sensor network, gray prediction, ZigBee

\section{Introduction}

The widespread promotion of the global energy internet has gradually increased the demand for electrical energy. Therefore, companies need to provide a variety of supplies to meet people's living needs. However, power plant boiler accidents occur frequently. According to statistics, the leakage of power plant boilers accounts for a large proportion of all boiler accidents. A serious leak prevents the normal operation of a power plant boiler. Such accident not only affects the economics of the power plant but also pollutes the environment. Therefore, the leakage status of power plant boilers should be monitored. On February 3, 2013, a boiler explosion occurred in Cixi, Ningbo. Most of the three-story buildings on the site collapsed, thereby causing 
five deaths and six injuries. On April 17, 2015, a boiler explosion at the Qingdao Blanket Factory caused a fire. Dozens of fire engines arrived at the fire site to rescue the workers. Unfortunately, two people were injured.

\section{State of the art}

In power plant boiler testing, leak detection devices have been used in the market before 1990. These simple devices consist mainly of analog conversion, amplification, and control devices and signal processors. The rapid development of industrial technology has enabled integration of integrated technology with the original complex signal processor and control display components into the main control system, thereby making the system more structured than before. Chen and Wang [1] studied the boiler of a power plant and considered it as the main equipment for energy supply. The safe, stable, and efficient operation of a power plant is important to guarantee people's normal production and life. Fan et al. [2] believed that the equipment of a power plant boiler is relatively large and difficult to replace. The power plant boiler is also prone to frequent failures. This condition not only results in the loss of production and living but also causes the destruction of the environment. At the same time, such accident often leads to serious casualties. Gürtürk and Oztop [3] reported that domestic boiler accidents in the period of 2011-2014 accounted to 29, 24, 19, and 22, respectively. Boiler explosion results in serious impact and strong explosion. This accident not only damages the building but also causes serious consequences, such as death. Li et al. [4] argued that ZigBee is a local area network with low cost, simple operation, low complexity, and low power consumption during operation. This technology has a wide range of applications in short-range wireless sensor network communications.

The development of modern sensor technology has gradually changed transducers from analog to digital. The preamplifier circuit in the original system is integrated into the sensor. At this point, the structure is integrated into two parts, namely, the main control system and sensors. The rapid development of network technologies in the beginning of the 21 st century has enabled the gradual shift from cable monitoring methods to wireless monitoring methods. Mylläri et al. [5] investigated Internet-based remote boiler leakage monitoring technology seminars and developed next-generation wireless monitoring technologies to create a new generation of Internet monitoring and demonstration systems. At present, some U.S. companies have already developed equipment. For example, Gear Controller, developed by a U.S. company, is used in remote monitoring systems for large-scale transmission boilers.

After 1980, China used some simple boiler leak detection equipment in power plants. By the early 1990s, the rapid development of power plant boiler leak detection technology was continuously promoted due to the rise of the economy and discussions with other countries on technology. At this time, the first-generation power plant boiler leak detection equipment was generated and implemented in the power plant. To improve the service life of boiler equipment and the reliability of boiler detection technology, a second-generation product was developed on the basis of the 
first-generation boiler. The typical representatives are the XLB-type testing equipment designed by Nanjing Huadian enterprise and the HDE-II power plant boiler detection system designed by Jiangxi Huadian enterprise. The BLD monitoring system, designed by Northeast Dianli University, is currently applied to the Jilin Power Bureau's power plant. Boiler leakage online monitoring systems are also widely used in various power plants at present. Many studies have been conducted on the basis of remote monitoring methods. Protivínský and Krejsa [6] proposed a real-time online monitoring system for power plant boilers based on data packet forwarding technology and the Internet. A boiler remote monitoring system was designed using configuration software and data packet technology. Shi et al. [7] proposed a remote monitoring system based on the Internet of Things. These systems are suitable for a small number of monitoring nodes. The cost of remote monitoring is huge and the stability is poor when the number of monitoring points is large. Therefore, these methods are unsuitable for remote monitoring. Zhang and Dojen [8] applied ZigBee technology to power plant boilers but on the basis of limited theories.

In summary, the accurate assessment of leakage status is the premise and basis for the failure status of power plant boilers. Current local and international studies on this topic are still in preliminary experimental period. Some studies use the 1-9 scale method in the analytic hierarchy process (AHP) to analyze the assessment results. Then, gray target theory is used for evaluation on the basis of the characteristics of the system. The weight of the gray target theory is an extremely important parameter. Other studies have proposed AHP and entropy weighting methods to solve the weight problem in leakage status assessment. The use of a single method may result in errors due to objective factors. Thus, weights are determined by combining the entropy weighting method with AHP. The ZigBee-based online monitoring system for gas leakage in power plants solves the above-mentioned drawbacks. This method is practically important for the monitoring of power plant boilers and provides a new means to ensure stable supply of electricity.

\section{$3 \quad$ Methodology}

\subsection{Overall design of the system}

The ZigBee-based online monitoring system of gas leaks from power plant boilers is mainly composed of three parts: boiler gas leak detection node (wireless sensor node), ZigBee transceiver module, and terminal monitoring center (Figure 1). The ZigBee transceiver module includes a ZigBee router node and a ZigBee coordinator node. Wireless sensor nodes collect data and process them through sensors. The processed data are sent by the wireless sensor module, and then forwarded by the ZigBee router several times, and finally received by the terminal monitoring device. The system can realize three functions: real-time detection of boiler environmental status data, wireless real-time transmission of boiler environmental data, and terminal monitoring center data analysis. 
The function of terminal monitoring center data analysis is discussed as follows. After the data are received by the terminal, they are processed and restored to the status data of the boiler. The monitoring center displays the environmental data of each boiler in a curve manner through the analysis software and compares them with the normal working boiler parameter reference to assess whether the boiler is working properly. Figure 1 shows the general block diagram of the system.

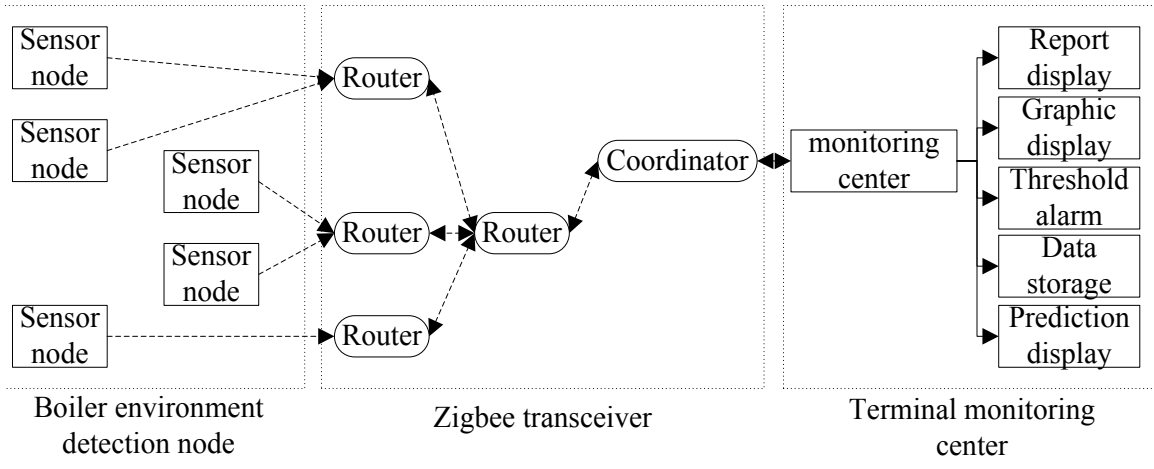

Fig. 1. General block diagram of the system

\subsection{Hardware design of wireless sensor node}

The hardware design of this system is divided into four parts: wireless sensor node hardware, ZigBee router node hardware, ZigBee coordinator node hardware, and terminal monitoring center module hardware designs. The core of ZigBee module circuit is the circuit design of data processing module, the design of antenna module, and the circuit design of power supply module. The design of the peripheral circuit is mainly the storage circuit of secure digital card. Figure 2 shows the schematic of wireless sensor nodes.

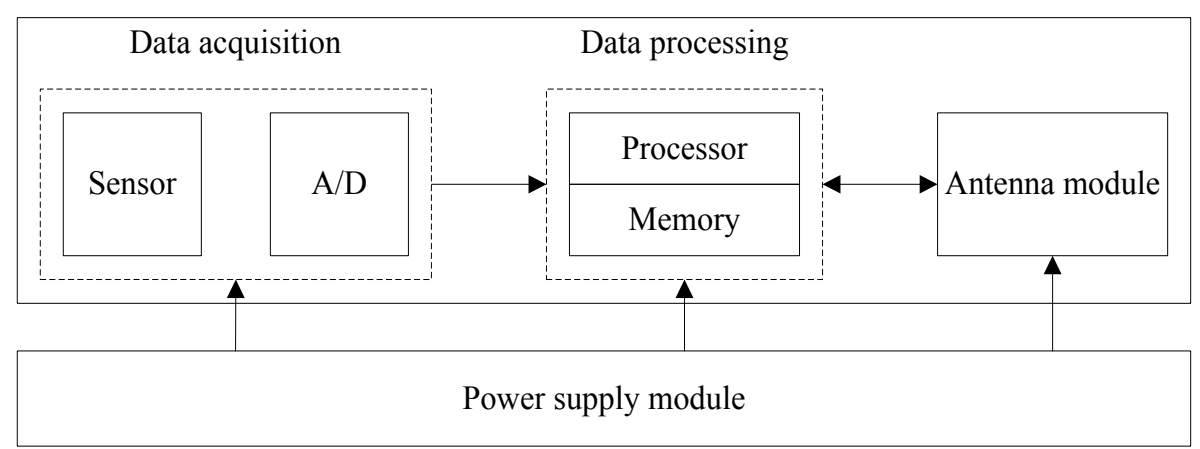

Fig. 2. Composition schematic of wireless sensor nodes 


\subsection{Hardware design of router node}

The router node consists of three parts: power supply, antenna, and data processing modules. Figure 3 shows the hardware structure relationship among the three parts.

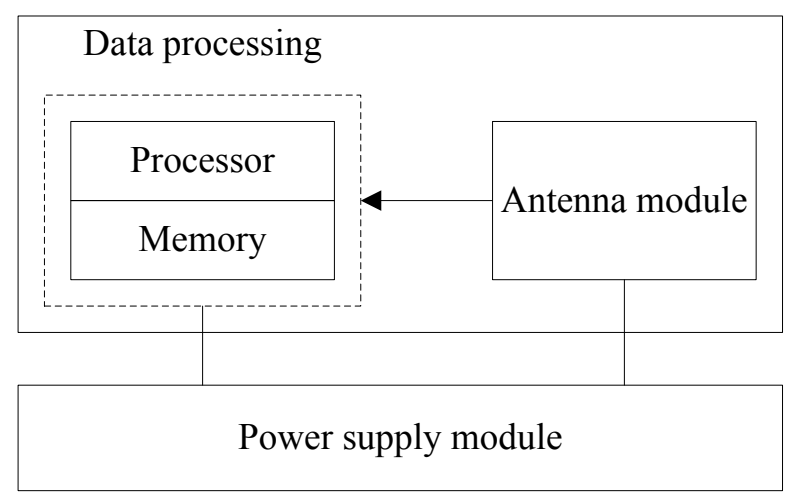

Fig. 3. Block diagram of the router

The main function of the router, which is a first fault detection (FFD) device, is to transmit the data. Under normal working environment, three sections of five batteries are used for power supply. The number of the routers is based on the effective communication distance under the environment. When the environment is complex, the effective communication distance is short. However, when the coverage of the system is large, only the router nodes can be added to achieve the stable transmission of data. The routers are added to transmit data in two ways. One is packet selection routing forwarding, and the other is packet relay forwarding.

\subsection{Hardware design of coordinator node}

The coordinator completes the tree network processing and the forwarding data task for the core equipment in the monitoring system. The coordinator node is composed of four parts: power supply, serial port circuit, data processing, and antenna modules. Figure 4 shows the relationship between each module.

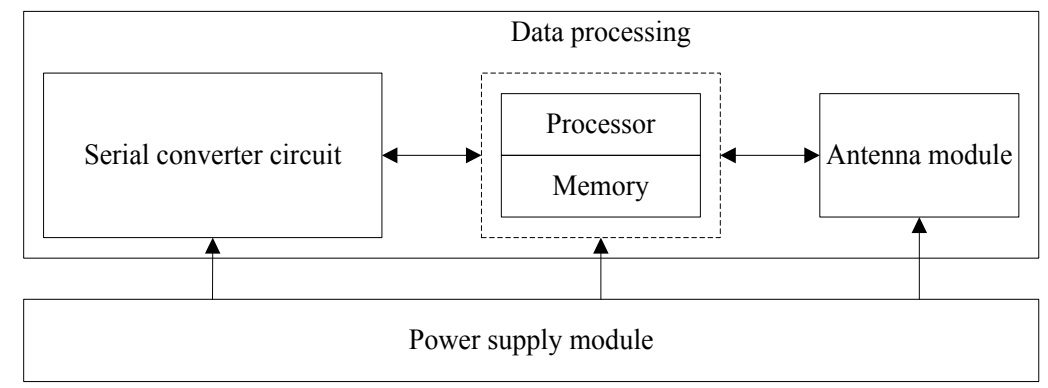

Fig. 4. Relationship between each module 


\section{$4 \quad$ Results and discussion}

\subsection{Software design of the overall system}

The A/D transforms the analog quantity into the digital amount. The data are transmitted to routers or coordinators through the ZigBee wireless transmission module. In accordance with the distance between the node and the coordinator, the nodes are chosen to transmit data. The terminal coordinator receives the data sent by the nearest router or direct sensor node and transmits them to the PC through serial port. Figure 5 shows the overall design flowchart of the system.

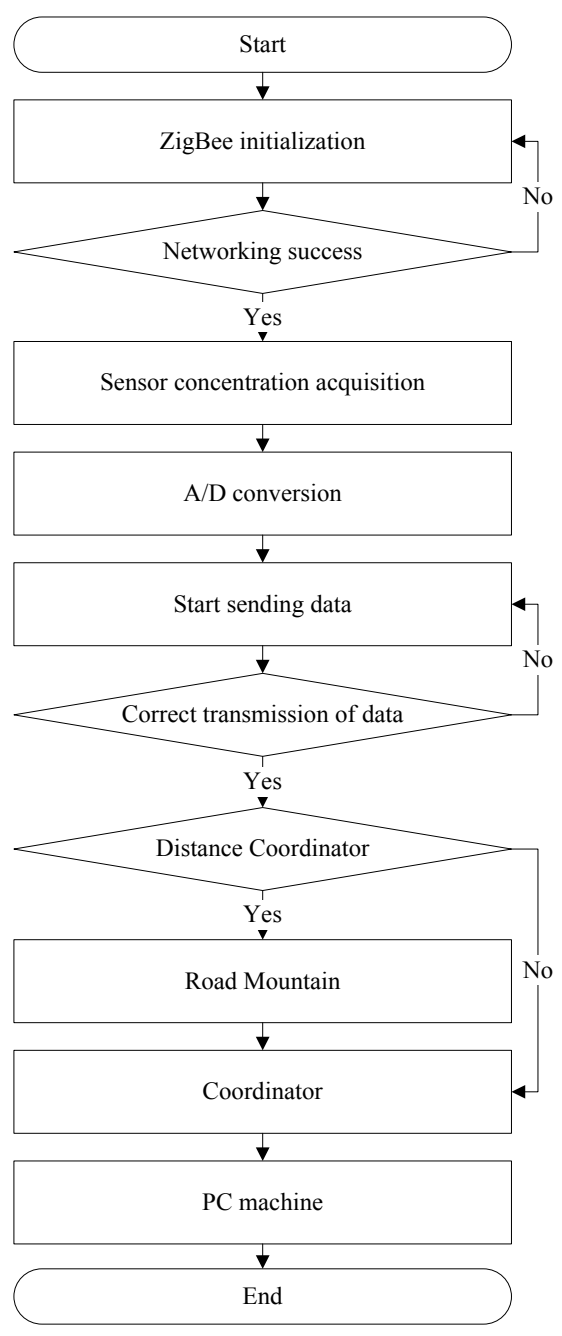

Fig. 5. Overall design flowchart of the system 


\subsection{Design of node program}

In this system, the sensor is installed near the boiler pipe of the power plant as a perceptual device. Its connection ZigBee module circuit is a sensor node with the function of real-time acquisition and transmission. This node includes power supply, data processing, and antenna modules and a sensor circuit. The implementation of this node is simple. The FFD node can be used as the node, and reduced function device can also be used as the node. At the same time, the node can work offline. However, the node can only complete the collection and sending function but cannot realize the information forwarding function. Therefore, the sending function can only communicate with its father node. Figure 6 shows the design process.

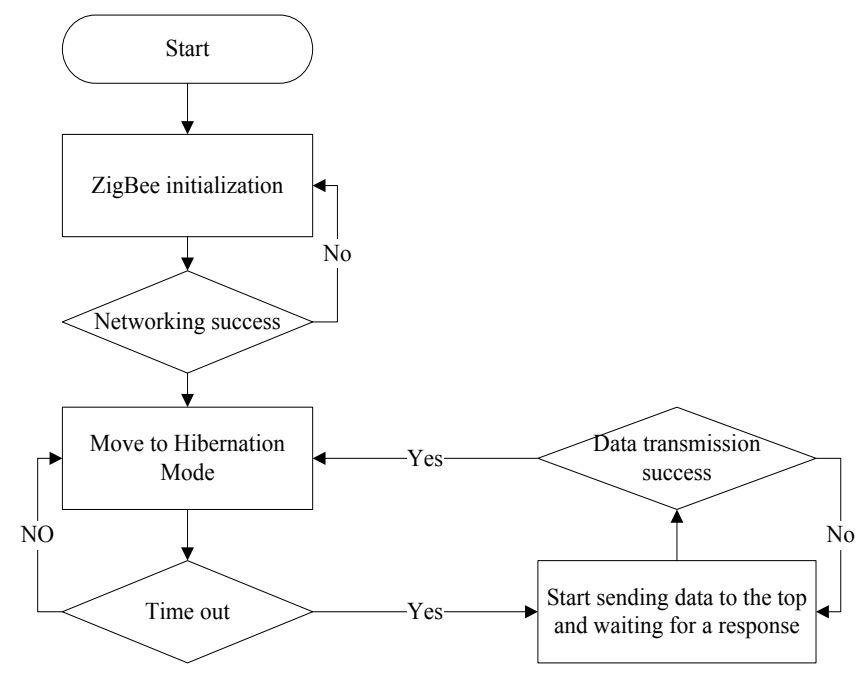

Fig. 6. Flowchart of the sensor program design

Compared with the design of the sensor program, the design of the router is simple. The latter design does not realize the acquisition function of sensor and only completes the forwarding of information, and it is usually placed between the two other two nodes, thereby playing the role of routing. When the distance between the two other nodes exceeds the effective communication distance of the data transmission, the router node will relay the data as the relay. The number of the routers in the network determines the network coverage area. A large number corresponds to a wide coverage. After the router starts the device, it initializes the device and enters the networking stage to determine whether the node is in the network successfully. If the network is successfully joined, then the request is sent to it. If the parent node is a router, then it sends the request to the upper layer until it is uploaded to the coordinator. If the parent node is a coordinator, then the address is allocated directly to it. Thereafter, it continues to enter the real-time monitoring state of the signal and is always waiting for the signal to receive. Figure 7 shows the specific design process. 


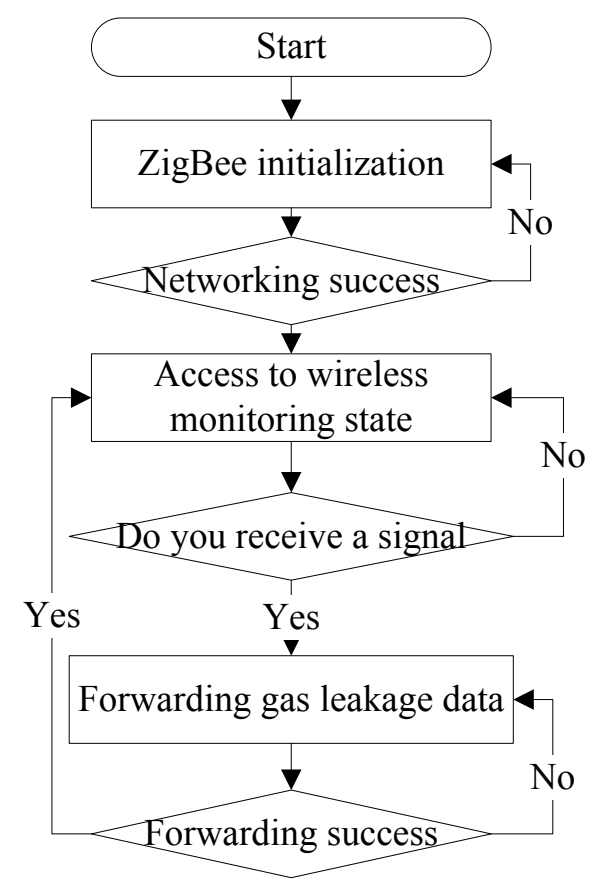

Fig. 7. Flowchart of the router program design

The coordinator is a two-way communication device. It not only receives data from routing forwarding or sensor sending but also sends the processed data to the PC terminal, which plays a core role in the network. If no coordinator exists in the network, then the network topology cannot be constructed. In the network, the coordinator mainly completes the task of setting up the network, distributing the address, accessing the network of the device members, and updating and forwarding the routing tables. The sub devices of the network are managed. The function of the coordinator is more complex than that of the two of nodes above. Therefore, the coordinator not only has high requirements on hardware devices but also needs additional program design on the basis of the above nodes in software. Figure 8 shows the specific implementation process.

The network process is the same as other nodes. In wireless monitoring, the signal must be analyzed after its reception. Whether the received signal is the signal uploaded by the sensor or the network signal of the node should also be determined. Depending on the type of signal, different program segments are executed. If the signal is uploaded by the sensor, then the signal is transmitted through the serial port to the PC terminal. If the signal is sent to the network, then the coordinator assigns the network address to the sub device of the network. 


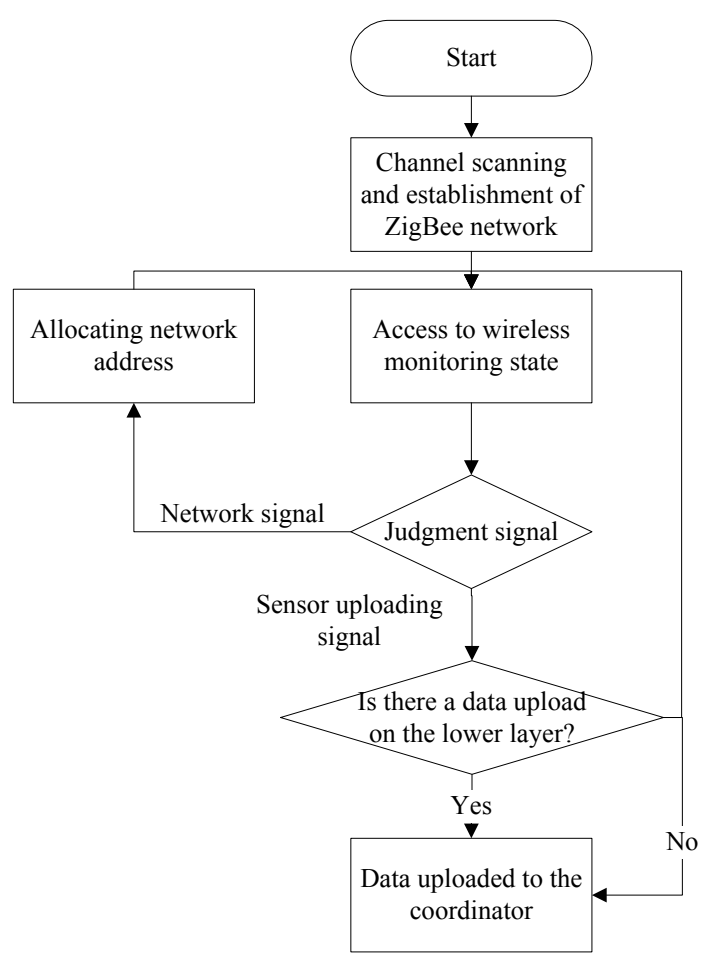

Fig. 8. Flowchart of the coordinator program design

\subsection{Software design of monitoring center}

The gas leakage concentration data reach the monitoring center through the ZigBee wireless transmission module. The monitoring center is mainly completed by the monitoring system management software. Management software is mainly composed of report display and real-time curve queries, leakage state evaluation, prediction display, and threshold alarm. Among these components, report display and real-time curve query are two methods mainly used to monitor gas leakage in real time. The leakage status assessment query can query the leakage of each monitoring point boiler and divide the running state into grade. Depending on different grades, the power plant boiler equipment is maintained. Prediction shows that the query can show the change rule of the gas leakage concentration at the next moment and can set the threshold alarm function. When the screen exceeds the specified value, the alarm will be issued to achieve the accuracy of monitoring the boiler gas leakage, thereby ensuring the normal operation of the boiler. Figure 9 shows the composition of the management software. 


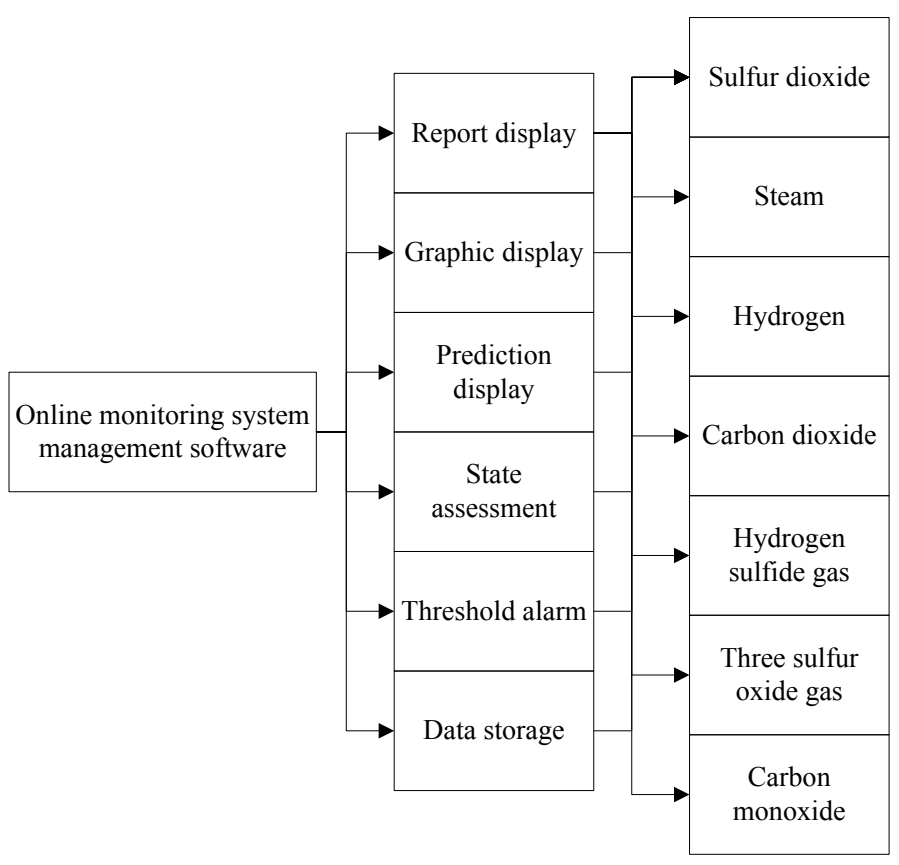

Fig. 9. Composition diagram of the management software

\subsection{Leakage state evaluation algorithm based on gray target theory}

The idea of introducing entropy weight gray target theory is to solve the equality problem of index weight in traditional gray target theory. The weights that correspond to the actual problem solving are unequal. The core of the entropy method is based on the degree to which each index pattern sequence changes. The information entropy concept is used to calculate an objective weighting method. Compared with the traditional gray target theory, the error of this method is very low. The specific process is discussed as follows.

First, the state index pattern matrix is constructed, the pattern matrix is singled out, and the characteristic proportion is calculated by Formula (1).

$$
e_{i j}=\frac{f_{i j}}{\sum_{i=1}^{m} f_{i j}}
$$

In the formula, $\mathrm{e}_{\mathrm{ij}}$ represents the characteristic weight of the $\mathrm{i}$-th state in the $\mathrm{j}$-th index mode in the sequence.

Then, a matrix $E=\left(e_{i j}\right) m \times n$ is constructed depending on the feature proportion. The entropy value of index $\mathrm{j}$ is obtained from Formula (2). 


$$
h_{j}=-\frac{\sum_{i=1}^{m} e_{i j} \cdot \ln e_{i_{j}}}{\ln m}
$$

Finally, in accordance with the entropy value, Formula (3) is used to calculate the entropy weight $\omega_{\mathrm{j}}$ under each index.

$$
\omega_{j}=\frac{1-h}{\sum_{j=1}^{n}\left(1-e_{j}\right)}
$$

AHP is a method used to deal with decision problems among multiple objectives through qualitative processing combined with quantitative processing. In the objective processing of data, the relationship between target system levels is analyzed following subjective experience. Usually, the two indexes are compared with each other. Then, the judgment matrix is obtained using the 1-9 scale method. Finally, the objective result is obtained. The process is discussed as follows.

To determine the correctness of the above-mentioned solution weights, the judgment matrix is tested using Formulas (6) and (7).

$$
\begin{gathered}
C R=C I / R I \\
C I=\frac{\lambda_{M A X}-n}{n-1}
\end{gathered}
$$

Table 1 shows the RI values of the $1-9$ th order judgment matrix.

Table 1. RI value table

\begin{tabular}{|c|c|c|c|}
\hline Matrix order & RI & Matrix order & RI \\
\hline 1 & 0 & 6 & 1.24 \\
\hline 2 & 0 & 7 & 1.32 \\
\hline 3 & 0.58 & 8 & 1.41 \\
\hline 4 & 0.9 & 9 & 1.45 \\
\hline 5 & 1.12 & & \\
\hline
\end{tabular}

In general, $\mathrm{CI}$ is acceptable when $\mathrm{CR}<0.1$. The consistency check is not satisfied when $\mathrm{CR}>0.1$. Therefore, the weight calculation result is incorrect.

When the above-mentioned consistency check is satisfied, the result of the calculation is the weight vector $\omega_{j}{ }^{\prime}$. The comprehensive analysis and entropy weight methods in the previous section are used to set the objective proportion and the subjective influence factor to occupy the same proportion and obtain the comprehensive weight. The target focus degree in the weighted model is 


$$
\gamma^{\prime}\left(f_{0}, f_{i}\right)=\sum_{j=1}^{n} \frac{\left(\omega_{j}+\omega_{j}{ }^{\prime}\right)}{2} \gamma\left(f_{0}(k), f_{i}(k)\right)
$$

\subsection{Prediction algorithm for gas leakage of a boiler in a power plant}

An online gas leakage monitoring system for power plant boilers based on ZigBee was designed for a power plant boiler in Jiangnan District of Jilin City. The feasibility of the GM $(1,1)$ prediction algorithm is verified using the concentration of the leaked gas, that is, $\mathrm{SO}_{2}$, as the sequence to be measured. In the experiment, a set of data was collected every $93 \mathrm{~s}$, and 10 data were used as a set of prediction models to predict the change of gas concentration leakage of $\mathrm{SO}_{2}$ in the time period of 2016-03-19 19:00:37 to 2016-03-20 01:10:24. The prediction implementation process is shown in Figure 10 , and the specific process is shown as follows:

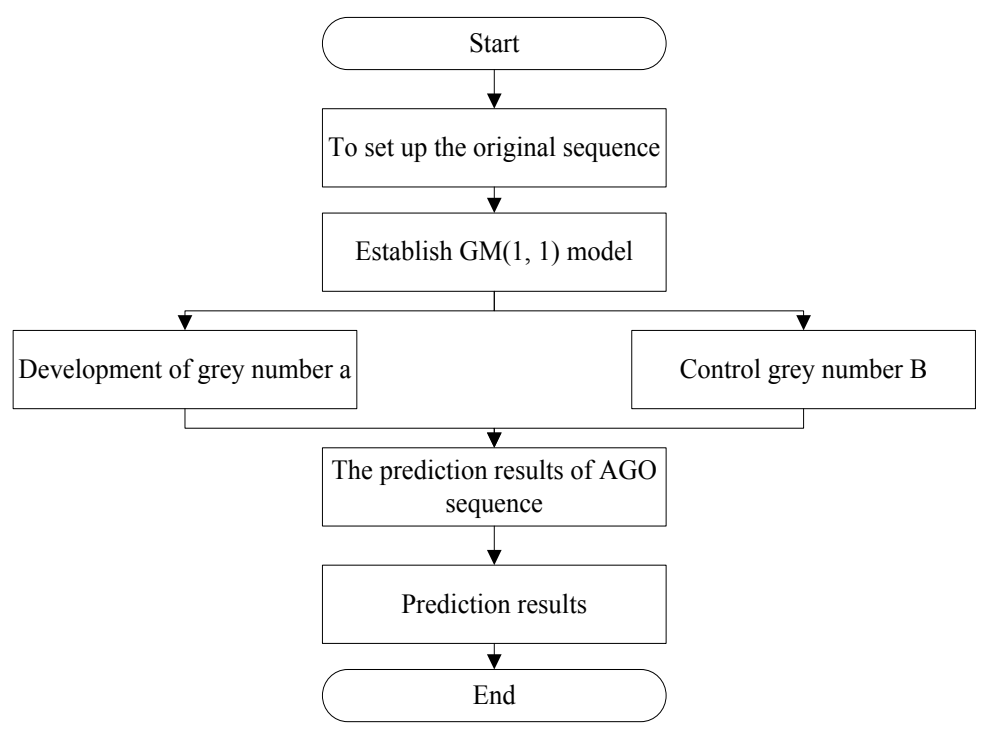

Fig. 10. GM $(1,1)$ prediction flowchart

With any set of data in the time period, $\mathrm{n}$ is taken as 10 , and the original sequence is set up.

$$
x^{(0)}=\left(x^{(0)}(1), x^{(0)}(2), \ldots, x^{(0)}(n)\right)=(54,49,54,57,55,53,51,52,51,55)
$$

The first-order cumulative operation is carried out.

$$
x^{(1)}=\left(x^{(1)}(1), x^{(1)}(2), \ldots, x^{(1)}(n)\right)=(54,103,157,214,269,322,373,425,476,531)
$$

$\mathrm{a}=-3.1156 \mathrm{e}-004$ and $\mathrm{b}=52.9089$ after calculation using differential equations.

The prediction result of AGO sequence is 


$$
\hat{x}^{(1)}(k+1)=0.16988 \mathrm{e} 6 * \exp (0.31156 \mathrm{e}-3 * \mathrm{t})-0.16982 \mathrm{e} 6 .
$$

The prediction result of the original sequence is

$$
\hat{x}^{(0)}(k+1)=\hat{x}^{(1)}(k+1)-\hat{x}^{(1)}(k)=52.917 * \exp (0.31156 e-3 * k) .
$$

\section{Conclusion}

First, the overall architecture of the system implementation process is designed. Then, the three-node program flow of the system is introduced in detail. Thereafter, the design of system networking and software management is completed. Finally, gray target theory of entropy weight is introduced. On this basis, the gray target theory algorithm of level entropy weight is proposed and applied to the online monitoring system of gas leakage in power plant boilers. During the period from 2016-03-19 19:00:37 to $2016-03-20$ 01:10:24, the GM $(1,1)$ algorithm was used to predict the evolution of one of the leaked gases (i.e., $\mathrm{SO}_{2}$ ). The boiler operation status is evaluated using the hierarchical entropy gray target. The prediction of gas leakage from power plant boilers and the assessment of leakage status are realized.

\section{References}

[1] Chen, S. H., \& Wang, C. P. The application of gray theory on wire cut electric discharge machine non-resistance sparkle circuit prediction. International Journal of Advanced Manufacturing Technology, 2018, vol. 95(5-8), pp. 2811-2820. https://doi.org/10.1007/s00170017-1317-7

[2] Fan, H., Wang, X., Ru, X., Fan, H., Wang, X., \& Ru, X., et al. A study of mineralization of wutai gold deposits in shanxi province based on the weight of evidence-singularity-gray theory. Geological Bulletin of China, 2017, vol. 36(8), pp. 1462-1466

[3] Gürtürk, M., \& Oztop, H. F. Exergy analysis of a circulating fluidized bed boiler cogeneration power plant. Energy Conversion \& Management, 2016, vol. 120, pp. 346-357. https://doi.org/10.1016/j.enconman.2016.05.006

[4] Li, J., Cao, Y., Ying, Y., \& Li, S. A rolling element bearing fault diagnosis approach based on multifractal theory and gray relation theory. Plos One, 2016, vol. 11(12), pp. e0167587. https://doi.org/10.1371/journal.pone.0167587

[5] Mylläri, F., Karjalainen, P., Taipale, R., Aalto, P., Häyrinen, A., \& Rautiainen, J., et al. Physical and chemical characteristics of flue-gas particles in a large pulverized fuel-fired power plant boiler during co-combustion of coal and wood pellets. Combustion \& Flame, 2017, vol. 176, pp. 554-566. https://doi.org/10.1016/j.combustflame.2016.10.027

[6] Protivínský, J., \& Krejsa, M. Using scaled physical model for assessment of mechanical damping of power plant boiler structure. Perspectives in Science, 2016, vol. 7(C), pp. 287291. https://doi.org/10.1016/j.pisc.2015.11.044

[7] Shi, Y., Wang, J., \& Liu, Z. On-line monitoring of ash fouling and soot-blowing optimization for convective heat exchanger in coal-fired power plant boiler. Applied Thermal Engineering, 2015, vol. 78, pp. 39-50. https://doi.org/10.1016/j.applthermaleng.2014.12.002 
Paper-Thermal Sensor Boiler Monitoring based on Wireless Sensing

[8] Zhang, F., \& Dojen, R. EWAIP: An empirical wireless sensor network applications implementation platform. University of Oxford, 2014, vol. 26(1), pp. 14009-14013. https://doi.org/10.1109/FGCT.2014.6933226

\section{Author}

Aixia Duan, Yanling Duan and Qiuhong Wang are with North China University of Water Resources and Electric Power, Henan 45004, China.

Yongzhi Huang is with Rundian Energy Science and Technology Co., Ltd., Henan 450000, China. His research interests include wireless sensor network.

Article submitted 07 June 2018. Resubmitted 28 June 2018. Final acceptance 28 July 2018. Final version published as submitted by the authors 